\title{
Action Research Against Violence: An Experience from Southern Mexico
}

\author{
Carlos Cortez Ruiz
}

\begin{abstract}
This article reflects on an experience of action research aimed at improving the understanding of the problem of chronic violence, raising awareness of its causes and implications, and promoting initiatives that seek to combat it through the assertion of rights. The research was developed as part of a university diploma taught in two Mexican states where chronic violence is an issue. The diploma aimed to build and support networks that promote cooperation between social actors. The action research was designed to offer a shared space in which diploma participants could develop joint initiatives aimed at raising awareness of the nature and dimensions of violence, and to confront the problem. Through building trust, the experience resulted in the creation of new approaches to the complex problem of violence, and new ways to understand it.
\end{abstract}

\section{Introduction}

This article reflects on an experience of action research aimed at improving the understanding of the problem of chronic violence, raising awareness of its causes and implications, and promoting initiatives that seek to combat it through the assertion of rights.

The work was developed as part of a diploma taught under the aegis of the Autonomous Metropolitan University of Mexico. It was aimed at non-governmental social organisations interested in promoting initiatives to tackle situations of chronic violence at local and regional level. The diploma was taught simultaneously in two regions of Mexico, in the states of Chiapas and Guerrero. It was designed to offer a shared space in which participants could develop joint initiatives aimed at raising awareness of the nature and dimensions of violence, and to confront the problem. It sought to overcome some of the common difficulties posed by action research, such as those mentioned by Grant et al. (2008: 591), and to facilitate dialogue between different actors.

The experience demonstrated that it is feasible to create a space, such as that created by the diploma, to provide a forum through which a broad range of diverse individuals could reflect together and share knowledge, generate innovative approaches to the complex problem of chronic violence, forge new ways of understanding the problem, and identify proposals for action aimed at combating its causes and implications. We believe that the experience could be successfully adapted to other contexts.

Up until now, most of the initiatives which have been generated as a result of this experience have been aimed at creating or supporting networks that promote cooperation between social actors. There has been less interest in seeking to influence public policy in order to combat different forms of violence. No initiative has emerged aimed at directly influencing the legal sphere, although it is possible that such actions may be developed in the future. The results of the initiatives which have resulted from the experience will become clearer in the medium term.

\section{Why research violence?}

Violence is present in a broad variety of social, cultural and political situations, a fact which suggests it may be universal in character. In his work on human destructiveness, Fromm (1973) notes the emphasis authors have placed on the 
assertion that the aggressive character of mankind [sic] is innate. He considers that this focus constitutes an attempt to avoid the need to investigate the causes of destructiveness, an analysis which Fromm believes should be rooted in the study of social systems. Some recent work deals explicitly with this relationship between violence and power.

We understand violence to be a collection of actions aimed at maintaining control over the ideas, values and interests, or the capacity to act, of an individual or group through the employment of some form of physical and/or psychological aggression designed to generate fear. It implies the violation of the rights of those who are affected. The concept of chronic violence is used here in the sense suggested by Pearce, who locates it in 'contexts where acts of violence are recurrent in different spaces and over time' (2007: 7). Citing Galtung, she notes that 'Direct violence is retained as a distinct form of violence, however, it is extended to reveal its impact on a range of human needs ... [while] structural violence has exploitation as its central characteristic' (2000: 16). Structural violence is the result of a range of social, economic, cultural and political relationships that maintain social groups in a situation of exclusion and deny them their rights, affecting their daily lives and acting to keep other kinds of violence alive. In the case of multicultural societies, violence may result from the impossibility of achieving intercultural dialogue in contexts characterised by different ways of understanding values and norms, or the mechanisms by which one group regulates the social life of others.

In this article, we recognise that it is important to consider the social dimensions of the problem. We propose that, by means of a process of collective reflection, it is possible to pass from a situation where violence is accepted to the identification of social initiatives to combat it (Pearce 2007). For this to happen, it is necessary to develop a form of research which not only enables greater understanding of the causes and implications of violence in a given society but also allows people to understand that they are able to do something about it.

This kind of action research requires that the affected population should be provided with a forum that enables them to participate directly or indirectly in reflections on the problem and its systematic analysis. This should be a space which advances understanding and also generates actions capable of interrupting the cycle of chronic violence and helps the population realise its rights. We believe that the space created as a result of the diploma has enabled these objectives to be fulfilled.

\section{Research designed to promote action against violence: the proposal behind the diploma}

The proposal to reflect on social action against violence and in defence of human rights came from the Violence, Participation and Citizenship thematic group of the Development Research Centre (DRC). ${ }^{1}$ In the case of Mexico, the action research was carried out by a group of academics and postgraduate students of rural development at the Autonomous Metropolitan University, all of whom have carried out action-oriented research in the states of Chiapas and Guerrero. Both states have a sizeable indigenous population, ${ }^{2}$ the majority of whom live in extreme poverty and face varied forms of social exclusion. Both situations are characterised by factors which mark them as regions of chronic and sustained violence that occurs in varied scenarios (Human Rights Watch 1997; Peace Brigades International 2008). In both areas, community-based organisational processes exist which seek to respond to a wide range of problems, but violence was not previously uppermost in their analysis of the problems.

The first phase of the research involved the creation of a working group whose members were interested in reflecting on the causes of violence and the social processes that seek to combat it. The group consisted of members of civil society organisations working in the fields of human rights, health, education and justice, principally with the indigenous population. The members of the group expressed interest in exploring new focuses which would enhance the collective ability to visualise, gauge and combat violence. The education, health and justice systems were identified as privileged spaces apt for the promotion of initiatives which might make it possible to break the cycle of violence and to advance the rights of the excluded sectors.

The central focus of the proposal consisted of the development of the diploma 'Social Action 
against Violence and for the Promotion of Rights'. The diploma served to facilitate a space which encouraged reflection and the construction of collective knowledge through the interweaving of research, training and action. The experience brought together people with different experiences and educational levels including community outreach workers who had completed only primary education, the professionally qualified, and students with varying levels of education. All were linked with a range of civil society organisations actively engaged in work to advance the rights of the population.

The diploma was intended to construct a 'learning community' as defined by Gómez (2004): a space which facilitates collaboration, dialogue and mutual feedback between different interest groups and promotes collective reflection, the sharing of knowledge and the generation of new ideas. If by its nature, research is a complex and systematic activity, it becomes more so here, given the need to link it to daily practice and to understand it as a means to generate alternatives to violence.

The work was carried out simultaneously in the two locations. In both cases it was organised around a group of 15 individuals who met in five three-day sessions each month. The process was divided into two periods. The first occurred during the meetings, and the second when the participants returned to the places where they worked. The hope was that the participants would absorb the methodology, and then replicate it in their reflections with the civil society organisations they work with. In this way the action research could be carried out simultaneously with different groups. One of the participants, an outreach worker with the NGO Health and Community Development (Salud y Desarollo Comunitario - SADEG) in Chiapas, described their relationship to the project as follows:

Those of us working in civil society organisations have a twin commitment: not only to approach the question of violence analytically, but to involve a greater number of actors in order to develop linked initiatives ... at SADEC we seek to implement a health programme capable of combating violence in the course of what we do in our daily work, that is through the process of training community activists.
Whenever possible, the communities were expected to maintain communication in order to reflect together on their experiences. The objective was to better understand violence and its causes, making the connection between what occurs at the intimate level between couples, and in the private and public spheres, within families and communities, respectively. By recognising that the individual situation of violence is part of a collective problem it becomes possible to identify public and private actions that may be developed in response. It becomes possible to recognise that in order to respond to the need people have to live without violence, it is necessary to satisfy other needs and to modify social, economic, cultural or political relations that reproduce chronic violence. The more deeply these relations are questioned - for example concerning the nature of the State or the ways power is exercised - the more likely it is that radical responses will ensue. Equally however, it may be concluded that it is impossible to do anything in the face of the complexity of the structures it would be necessary to transform.

The exercises carried out during the course of the diploma sought to develop the capacity of the participants to reflect on events in their localities. Participants were required to jointly identify the topics they would take back to their organisations and to propose ways in which they would reproduce the discussions there. In this way, the direct participants in the diploma, and the hundreds of people indirectly involved through their activities in the organisations, increase their ability to visualise the problems associated with violence. This means of reflection made it possible to obtain important empirical evidence about how violence is perceived, visualised and understood, as well as the changes that occur with these perceptions. In order to assist with this process, the testimonies and reflections of the participants were recorded on video.

Describing the different kinds of violence, one participant, a community worker from the Casa de Salud in Guerrero, observed: 'In my community there are many land problems, and people have been killed as a result of them. There's also violence in the families, between brothers and sisters, affecting children; and between couples'.

Different techniques, such as participatory video recording and the conducting of interviews, were 
suggested by members of the DRC and were used to facilitate reflection on and analysis of the experiences of violence. This combination of methods made it possible to increase the involvement of the local population.

Analysis of actions to combat chronic violence, whether developed previously by the diploma participants or by other actors, provided evidence that it is possible to break the circle of violence by way of different kinds of social initiatives. By systematising previous experiences, it was hoped that the participants would learn which aspects to take into account if they are to act to combat violence in similar situations, especially when incentives exist that pull in the opposite direction.

Experiences analysed as part of the process included cases where several of the participating NGOs responded to situations of intracommunal land conflicts that had been exacerbated by the intervention of state authorities. The analysis made it possible to design some coordinated actions to monitor the problem and to continue working for the release of individuals who had been unjustly detained.

Collective reflection using participatory video meant it was possible to identify stories or situations that, because they illustrated certain common problems, were held to be representative of different kinds of violence. This made it possible to identify common causes and possible remedial actions. These stories were used as the basis for the elaboration of scripts which were acted out by the participants and videoed. The process of preparing the videos involved the identification of a theme the participants felt was important; the elaboration of a story based on real facts; the collective elaboration of a script designed to illustrate the problems and identify possibilities for action and the presentation of the story by the participants. The videos became tools that enabled the participants to take their reflections back to their work environments, where violence is experienced directly, and to help to deal with the problem there.

The topics covered in these stories included forced marriage and domestic, intra-family violence; the land rights of women; intracommunity religious disputes; disputes over the appropriation of natural resources and the role of the state in maintaining and reproducing violence. All of these are common problems in the chronically violent regions covered by the diploma.

In order to gauge the dimension of the kinds of social violence narrated in the participatory video stories, the DRC thematic group suggested that a survey should be carried out. A questionnaire based on a series of proposed themes was elaborated collectively by the diploma participants. The result was an extensive version consisting of 130 questions. This was difficult to apply, especially because it was necessary to translate the questions into the seven indigenous languages spoken in the communities. The questionnaire included questions on socioeconomic circumstances in order to ascertain some of the causes of violence associated with poverty; and on the relationship between alcoholism, drugs and violence. It also included questions on communal and intercultural violence, and ended with questions on the evolution of violence. Several of the participants spoke one or more of the indigenous languages, which meant it was possible to apply the questionnaire to the most far-flung and excluded populations. The questionnaire enabled the participants to deepen their understanding of the problem of violence.

\section{Additional to the linguistic problems} encountered, there was some resistance and other difficulties associated with carrying out the survey. For example, one community worker who was applying the survey in a community was threatened by members of the local authority. The worker would not allow intimidation, and asserted the right to engage in the activity, thus gaining recognition as an important promoter of actions against violence and in defence of rights.

One group of human rights activists had the following experience when they were applying the questionnaire:

we had told the people that we were organising a session to present a questionnaire ... We presented it to a community of displaced people ... almost all of whom spoke Tzeltal. We realised that, because of the nature of the questions, it would not be possible to apply it collectively. Initially only the men wanted to speak [because] the women did not speak Spanish. 
The way in which the survey was applied, and the utilisation of the information generated, enriched the original perspective of the participants and enabled them to compare the situation in the two states. We return to this question below. Once the results were ordered, they were analysed and interpreted collectively allowing the participants to gain a broader understanding of the dimensions and nature of the problem of violence. This is why we refer to a participatory survey: it was elaborated collectively and applied by the different participant groups before the information gathered was analysed collectively.

The learning community then worked further on the four themes that had been identified as priorities: visualising violence, the dimensions of violence, social experiences in violent contexts, and initiatives to combat violence.

The motivation for identifying the first theme was to understand the population's views of violence. Building on the recognition that there are different expressions of violence that affect the intra-family level as well as within and between communities, the communities looked at what they could do to ensure that questions of violence were recognised publicly rather than remain hidden in the private sphere.

This problem was initially approached through a reflection on how different individuals understood violence and what significance it had in our lives. This made it possible to recognise the different kinds of violence and the physical, psychological, emotional and symbolic effects these violations of human rights have on individuals and communities. The intention was to start with a focus on the individual social and historical situation, understood as a complex problem that may be explained as a result of the interaction between cultural, psychological, political and economic factors.

Given that the objective of the process of reflection was to identify initiatives to combat violence, it is important to take into account all the factors that contribute to or facilitate it, such as alcoholism associated with machismo, political disputes, or the increasing violence resulting from religious differences. In regions such as those covered by the research, whose population is overwhelmingly indigenous, cultural differences lead to numerous and varied tensions and expressions of inter-cultural violence.

One part of the research was aimed at measuring the problem of violence in the hope of constructing a quantitative and qualitative understanding of the problem in its family, community, intra-community and intercultural aspects, with an emphasis on the role that state institutions play in its reproduction. So as to arrive at a preliminary understanding of the role violence plays in our lives, an exercise was carried out in which each participant prepared an image that represented their lives and showed how much violence there was in it, in such a way that the fuller the image, the more violent the life had been. Each participant then reflected on the role that family, community or social violence had played in their lives.

Central to this reflection on the dimensions of violence was the survey. A total of 100 questionnaires were applied in Chiapas and 200 in Guerrero, although only the first 85 of these to be completed were analysed by Justino $\mathrm{et} \mathrm{al}$. (this IDS Bulletin). Because of the way it was applied, and the reasons for choosing the methodology, this technique did not provide the rigour of a statistical survey, but it did prove to be extremely useful. The survey made it possible to understand the dimensions of violence and to differentiate between its different expressions, taking into account such aspects as social position, ethnic group, gender, age-group, culture and traditions. In processing the information, it was possible to present the results in simple graphic form. This enabled the participants to carry out their own analysis of the information, locating their local experiences in context, and reflecting on violence from a regional perspective (see Justino et al., this IDS Bulletin). In a final session, the Chiapas and Guerrero groups used the information generated by the survey to present their analyses of the problem of violence along with the initiatives they proposed to develop to combat it.

The aim behind reflecting on the experiences of community action to combat violence was to facilitate learning and to consider the conditions necessary to continue to act to combat situations of chronic violence. It also aimed to identify other actions that could enable communities to act, especially given the persistence of incentives 
that might encourage them to desist. This would increase their ability to combat violence and to go beyond denunciation of incidents to develop actions designed to demand the fulfilment of rights. Because they had not previously been in a position to carry out this kind of activity, the systematic analysis of varied experiences proved to be of great interest to the participants and opened up to them the possibility of enriching their practice.

During the development of the diploma, various violent incidents occurred. Some of the participants denounced them publicly, and responded to them, with medical or legal services offered to those affected. This provided an opportunity to reflect on the causes of the problems and to analyse the responses and their implications.

Proposals to combat the problem of violence were elaborated on three levels: those aimed at promoting collaborative networks between civil society organisations and social groups subject to chronic violence; those aimed at influencing public policy in order to prevent or combat violence and those aimed at promoting legal change in order to improve levels of efficiency in the prevention of chronic violence. At the end of the process, the central emphasis of the proposals was on the promotion and strengthening of social networks. Advocacy aimed at influencing public policies was not felt to be very feasible because of the high levels of distrust of government institutions; the same was felt to be the case in relation to initiatives to promote legal changes aimed at combating the different forms of violence.

\section{Conclusions}

It is possible to conclude that a diploma designed to create a learning community and to carry out

\section{Notes}

1 For more details on the research of Violence Citizenship and Participation thematic group of the Development Research Centre, see McGee, in this IDS Bulletin. action research constitutes a resource which makes it possible to increase understanding of a complex problem such as chronic violence and to identify potential social action to combat it.

The conceptualisation of the diploma as a learning community made it possible to create a space which responded to the interests of different groups - from community workers interested in identifying alternative ways of working, to academics concerned with developing informed methods to combat problems effectively. The diploma allowed the participants to influence each other over their concerns, their ways of understanding, and also to use the knowledge that was generated. While it may be too soon to evaluate the effects of the community initiatives aimed at combating chronic violence in the regions where it operated, it is important to note that several participants did start such initiatives. The method, then, is shown to be of benefit in the identification of different actions which seek to transform varied kinds of relations in order to guarantee the rights of sectors who experience different forms of exclusion.

The experience made it possible to establish relations of trust between actors with different though generally complementary - priorities and interests. In this way, a process of dialogue was established between different kinds of knowledge and ways of understanding, and this led to a process of reflection. This resulted in the creation of new approaches to the complex problem of violence, and new ways to understand it. As a result, those who took part were able to identify potential routes to action and transformation. We believe that the experience could be successfully adapted to other contexts. We trust that this article will prove to be a contribution towards this end.

2 According to official figures, in 2000, 6.7 per cent (approximately 6 million) Mexican inhabitants over the age of five spoke one of the 65 indigenous languages; most live in rural areas. 


\section{References}

Fromm, E. (1973) The Anatomy of Human Destructiveness, New York: Holt, Rinehart and Winston

Gómez, J. (2004) 'Metodología Comunicativa Crítica', in R. Bisquerra, Metodología de la Investigación Educativa [Methodology of Educative Research], Madrid: La Muralla

Grant, J.; Nelson, G. and Mitchell, T. (2008) 'Negotiating the Challenges of Participatory Action Research: Relationships, Power, Participation, Change and Credibility', in Peter Reason and Hilary Bradbury (eds), Action Research: Participative Inquiry and Practice, London: Sage
Human Rights Watch (1997) Implausible Deniability: State Responsibility for Rural Violence in Mexico, www.hrw.org/legacy/reports/1997/ mexico/ (accessed 27 September 2008)

Peace Brigades International (2008) Human Rights Defenders in the State of Guerrero, www.pbimexico.org/fileadmin/user_files/proje cts/mexico/files/Defenderes_Guerrero_PBI Mexico_ENG.pdf (accessed 25 September 2008)

Pearce, J. (2007) Violence, Power and Participation: Building Citizenship in Contexts of Chronic Violence, IDS Working Paper 274, Brighton: IDS 